\title{
TEACHING RESEARCH WRITING AT EXIT-LEVEL UNDERGRADUATE PROGRAMMES IN SOUTH AFRICA
}

\author{
E. E. Esambe \\ Fundani Centre for Higher Education Development \\ Cape Peninsula University of Technology \\ Cape Town, South Africa \\ e-mail: esambee@cput.ac.za
}

\section{ABSTRACT}

Not enough writing support is being provided to Baccalaureus Technologiae (BTech) students in vocational-intensive universities in South Africa. Even worse, not enough research is being done to investigate the writing attitudes of BTech students or how their lecturers support them in writingintensive subjects. This view represents an unfair and a discriminatory approach to providing learning support to BTech students. This article explores the use of dialogical formative feedback in the teaching of research writing to BTech students in a health sciences department at a university of technology in South Africa. The article uses Engeström's (1987) concept of an activity system in cultural-historical activity theory (CHAT) and Boud and Molloy's (2013a; 2013b) dialogical feedback approach to examine how formative feedback is being negotiated in a class of 14 Dental Technology students at a university of technology. Qualitative data was collected through focus group interviews, and from the written feedback on the students' assignment drafts. This data is read diffractively using activity theory, and dialogical feedback approach. This diffractive approach enables one to use theories to challenge hegemonic, discriminatory, and often unproductive models of feedback support in the teaching of research writing to students in difficult and uneven conditions. By diffractively reading practitioners' thoughts and actions iteratively over time through the relational ontological frameworks of activity theory and dialogical feedback, this article proposes a breakaway from the formal, prosaic, linear, and bureaucratic approach of giving feedback to students' writing which often does not impact student learning.

Keywords: formative feedback, research writing, diffractive methodology, activity theory, dialogical feedback

\section{INTRODUCTION}

The practice of teaching students how to write academically in the university falls within the growing field of academic literacies (Jacobs 2013; Lillis and Scot 2007). This field borrows quite substantially from and recognises the contributions of research from different institutional contexts (Lea 2016). There is also, increasingly, the use of an innovative blend of theories and methodologies (Lea 2016) in exploring the teaching of writing in particular and researching academic literacies in general. Lillis and Scot (2007) for example argue on the epistemological 
and ideological attributes of academic literacy, while Jacobs (2013) favours an ontological approach to understanding the academic literacy field. Following on this, English (2015) argues for a shift from genre approach to knowledge approach, while Clarence (2017), and Clarence and McKenna (2017) extend the argument to explore the place of disciplinary knowledge in the building of the academic literacy field. There is also the view that academic literacies work is often pushed to the peripheries of the curriculum (Thompson 2009; Robinson 2009), and as such, there is need to move it from the margins of the teaching and learning space to a more central positioning in the curriculum (Robinson 2009; North 1984). This view is clearly seen in the way vocational-intensive universities (often reffered to as universities of technology in South Africa) offer writing support to students at exit-level programmes. We already know that undergraduate students in science and engineering percieve writing activities and written assessments differently compared to students in other faculties (Fraser and Killen 2005), and that teaching of writing is represented differently and often contradictorily in terms of assessment goals and graduate attributes (Linder et al. 2014). It is this contradiction, otherwise known as tension in the language of Activity theory, that mostly needs mediation when supporting science students when they are completing intensive writing assignments. Dialogue is needed to achieve this. Freire $(1970,61)$ explains that "dialogue is the encounter between men, mediated by the world, in order to name the world".

The above brief background to academic literacy sets the stage for an exciting and innovative use of theory and methodology to explore writing practices within the context of a vocational-oriented university of technology. This article focuses on a diffractive reading of dialogical formative feedback during research proposal writing through the lens of culturalhistorical activity theory (CHAT). The aim of this research is to explore the efficacy of dialogical formative feedback in the teaching of research writing to BTech students in a science discipline. By so doing, this research will demonstrate how, by reading one theory through another and through reflection on practice, we can move student academic writing support from the margins of the curriculum and strengthen the way we support students' writing practices in a vocational-intensive learning environment. This approach represents a transformative way of providing research writing support to students in difficult and unequal settings. In using the words "difficult" and "unequal" in this article, I borrow from Gándara et al. (2003) who explained that when the quality of teaching and learning is relatively poor for a particular group of students compared to another group due to the influence of wealth, race, or otherwise, the affected group is considered to be learning under difficult and unequal conditions. This, Gándara et al. (2003) explain, is not only morally wrong but also open to legal challenge.

Dialogical feedback emerges from the seminal work edited by Boud and Molly (2013a) 
titled Feedback in higher and professional education: Understanding it and doing it well. This book suggests a radical shift from the authoritarian, one-way, talk down model of providing feedback from educators to students. It proposes a transformative, collaborative, and dialogical approach to designing and enacting formative feedback which allows for an active student participation in the process of crafting and implementing formative feedback. Such an approach also finds relevance with those who call for a co-authorship of the curriculum. As Freire (1970, 61) emphasises, "dialogue cannot occur between those who want to name the world and those who do not wish this naming". Using a diffractive methodology where we read the use of dialogic formative feedback through the lens of CHAT, this article suggests that there is potential to strengthen the practice of feedback and to contribute towards bringing voices in the margins of the curriculum to participate further in and move meaningfully towards engagements with knowledge and student success.

This research was conducted in the Department of Dental Technology at a university of technology in South Africa. Dental Technology is a highly vocational and artisan discipline (SADTC 2017; Christensen 2009) involving intensive and long hours of practice in laboratories. Such a discipline typically does not privilege writing as its practitioners are generally more interested in the design and manufacture of dentures, bridges, and crowns, and not in the writing of academic essays (Evans, Henderson and Johnson 2010). BTech students are students who have already completed the National Diploma in Dental Technology, and are registered as dental technicians with The South African Dental Technicians Council (SADTC 2017). Upon completion of the BTech qualification, these students can enrol as dental technologists with the council. One of the compulsory BTech subjects is Research Methodology, and the research proposal is one of the assessment for this subject.

\section{WRITING AS SOCIAL PRACTICE: CHAT}

Every writer writes from within a specific context. In the university, while students are expected to observe strict application of grammar and other writing conventions, the students' writings are also influenced by the discipline they are pursuing. The broader university setting, as well as the specific discipline from which the student is writing, demonstrate that writing is a social activity (Gee 2008). CHAT is an extension of the rapidly growing Vygotskian mediated learning theory called activity theory (Engeström 1999a). This theory argues that culture and history contribute significantly to how a subject acts on an object using tools (Hardman and Amory 2015). In the field of academic literacy, writing is an activity (Clarence 2017; Lea 2016). In this case, the students who are expected to write a BTech research proposal are the subject in the activity system (see Figure 1), and the proposal that will be written is the object of the 
activity system. This activity happens within an immediate environment, the Department of Dental Technology which will constitute the Community with its own rules of learning and assessment. The members of this community have different roles and responsibilities, constituting the division of labour component in the activity system (Esambe, Mosito and Pather 2016). In trying to understand how to support Dental Technology students during the writing of their BTech research proposals, we need tools that will help us to systematically unpack and analyse the factors that enable or constrain how these students write. CHAT does not only help us to analyse the process and use of formative feedback, but it also allows us to understand how cultural and historical factors contribute to this process.

\section{CONTEXT}

This article is set within the context of the provision of writing centre support as part of a holistic programme towards enabling student learning and retention of undergraduate students at a university of technology in South Africa. Coming from this backdrop, I was assigned to provide writing support to a class of 14 BTech students in the department of Dental Technology at a university of technology in South Africa.

The interventions from which the data in this article are extracted come from engagements in the Research Methodology class for the BTech 2015 cohort. Two lecturers (teaching Research Methodology and Dental Theory respectively) made official requests for writing centre intervention to support the BTech students in an integrated research project that they will co-evaluate. The writing centre intervention was structured as part of the students' tutorial programme, and meetings were planned on the teaching timetables. Twelve tutorial sessions took place over the course of 8 weeks between August and October 2015, culminating in the completion and submission of the students' individual research proposals. During the tutorial sessions, we adopted a multimodal collaborative approach comprising of seminars on research methodology, group discussions, online peer discussions, and one-on-one consultations with lecturers. The multimodal approach was useful because it allowed for the subject-specific lecturers to be involved in the writing centre interventions and provide expert contributions in terms of the content and disciplinarity of the students' research.

The BTech Dental Technology curriculum is intensely vocational (Evans, Henderson and Johnson 2010) and writing as a practice is not considered to be privileged in the discipline. A dental technologist works mainly in a dental laboratory and writing within their practice involves mainly correspondence and referral notes between the dental technologist and the dentist. Therefore, dental technology students are, logically, apprehensive and resistant to teaching and assessments that involve intense critical and prosaic writing. However, the BTech 
qualification is the bridge between the National Diploma (3-year diploma programme) and postgraduate studies. Thus, it is mandatory for research methodology to be introduced at the BTech level of studies. This background highlights the contradiction in how research writing is perceived, taught, and privileged in that curriculum.

\section{DIFFRACTIVE METHODOLOGY}

This study employed a diffractive methodology in order to explore the use of formative dialogical feedback to support a small class of BTech students during a research writing course at a university of technology. Diffractive methodology as used in this article allows one to read one set of data or ideas through another (Barad 2007). In this case, data from the BTech students and their lecturers is read through the prescripts of dialogical formative feedback, and further interpreted using CHAT. Purposive sampling was used to locate the research setting and participants. This was guided by the research aim. Qualitative data was collected for this study. This data was extracted through focus group interviews with 14 students and 2 subject-specific lecturers for Dental Theory and Research Methodology, and from the students' draft research papers. As the academic literacy lecturer and writing centre consultant for this group of students, I used Google Docs as an effective tool to share presentations and generate collaborative feedback (Rowe, Bozalek and Frantz 2013) on the students' draft research assignments. This feedback is also shared with the concerned subject-specific lecturers. Regular tutorial meetings were scheduled where the students presented drafts of their research projects and received formative feedback from their peers as well as from the writing centre and subjectspecific lecturers.

\section{DATA SELECTION AND ANALYSIS}

In selecting data for this article, the focus was on data that "glows" (Maclure 2013, 661) because the intention was to excavate meaningful personal information. Such information, extracted from the responses contained in the focus group interviews and students' draft research papers was analysed using Boud and Molloy's (2013a; 2013b) dialogical feedback framework and then read diffractively through Engeström's (1999b) CHAT. In using diffractive methodology one has to be alert and to observe key "glows" from a set of data or ideas while being aware of "important details of specialized arguments" (Barad 2007, 25) emerging from the other texts. A reading of Boud and Molloy's dialogical feedback diffractively through Engeström's CHAT opens up unique ways of seeing student learning support away from the vague and often centralised and authoritarian linear model (Dolphijn and Van Der Tuin 2012; Barad 2007). Barad $(2007,90)$ explains that diffractive methodology is a "critical practice for making a 
difference in the world", and to examine what difference matter and why they matter. In this way, diffractive methodology encompasses ethics with ontology and epistemology and has thus been described as an "ethico-onto-epistemological practice" (Bozalek et al. 2016, 4; Barad 2007, 26).

In this article, I explore the use of a dialogical formative feedback provision to exit-level undergraduate students through the lens of history and culture as agents in mediating or constraining the learning of research writing. In doing this, focus group interviews was one of the tools used to collect data. Focus group interviews took place immediately after each tutorial session that was organised. There were four focused group interviews post tutorial sessions each lasting an average of $15 \mathrm{mins}$. The discussion during the focus group interviews was framed to elicit information on whether the sessions were helpful and if it had met a specific writing need of the students. Basically, I wanted to know if we were "on the mark", "off the mark", or in-between (Bozalek et al. 2016, 5) in addressing the BTech students' research writing needs and concerns. Writing as an activity influenced the way the talking points in the focus group interviews were framed. At least 1 subject-specific lecturer was present at all the tutorials and during the focus group interviews. Their role was to ensure that the feedback and interventions done during the tutorials were aligned with the outcomes of their subjects and that certain discipline-specific learning objectives were met. Based on the feedback from the lecturers and the students during the focus group interviews, follow-up consultations with students who were deemed to need further attention and/or referrals were arranged. Such referrals were based on the challenges identified from the students' drafts and an identifying the most appropriate academic support stafff who can support the students. Such a consultative approach to providing formative feedback to students are captured in Boud and Molloy's (2013a) dialogical feedback approach. This feedback was again analysed diffractively through Engeström's (1999a) CHAT framework. This is considered to be a novel way of understanding writing centre support to BTech students because:

"a diffractive seeing or reading of the data activates you as being part of and activated by the waves of relational intra-actions between different bodies and concepts in an event with the data. As you read, you install yourself in an event of becoming with the data" [my emphasis]. (Hultman and Lenz Taguchi 2010, 537).

Intra-action evokes co-constitutive agency of human and non-human actions (Barad 2007). A diffractive reading of the data with a set of ideas (Boud and Molloy's dialogical feedback approach) through another (Engeström's activity system) ultimately ensures that there is a mutual co-sharing of meaning between the ideas and the data. This is similar to Barad's (2007) 
explanation of the process of diffraction using the analogy of the waves; how one wave combines and builds on another. Therefore, a diffractive reading allowed for new ways of seeing how we design and implement undergraduate student writing support initiatives, and to measure their efficacy without using numeric constructs.

This article was completed thanks to the active collaboration between the author, the 2 subject-specific lecturers, and the 14 BTech students who attended the tutorials, expressed their feelings and understanding of dialogic formative feedback interventions provided during the tutorials and engaged passionately in the focus groups interviews. This process allowed for regular consultation between us, and for on-going discussions with the BTech students and their lecturers. Where necessary, these discussions involved other stakeholders such as staff from the campus library and other student support units.

\section{AN ANALYSIS OF DIALOGIC FEEDBACK PROCESS THROUGH CULTURAL- HISTORICAL ACTIVITY THEORY}

In this section of the article, I examine BTech students' engagements and reactions to dialogical formative feedback which was provided by two discipline-specific lecturers and a staff member from the writing centre. I use the elements of an activity system (Engeström 1987) to analyse the role of dialogical formative feedback as a tool to improve BTech students' research writing (see Figure 1) and contribute to student well-being by motivating student learning. I therefore diffractively read some of the feedback that was provided, question how the feedback was generated, and examine the BTech students' responses to the feedback, and the impact of the feedback on the students' research writing, using the elements of an activity system (see Figure 1) in relation to dialogical feedback.

\section{Subject-object contradiction: They want different things}

The BTech student presents unique attributes that are under-explored in academic development literature in South Africa. BTech students are at an exit-level undergraduate programme that allows them to pursue postgraduate studies. However, there are strong concerns around the retention and throughput rates of postgraduate students in South Africa (Motshoane and McKenna 2014; CHE 2009; Gardner 2009; Herman 2011; Koen 2007) and that lack of adequate research attention to this concern (Motshoane and McKenna 2014). It is clear that widening access to higher education does not equate to sustaining quality learning for graduates (Prinsloo 2016). Tinto $(2014,6)$ cautions that "providing students with access without support is not opportunity”. As Hardman and Amory $(2015,9)$ put it, South Africa is a diverse and multilingual country "steeped in a history of unequal access to educational opportunities; clearly, to 
understand the subtleties of any transformative process in this country requires a theoretical framework capable of speaking to cultural and historical influences".

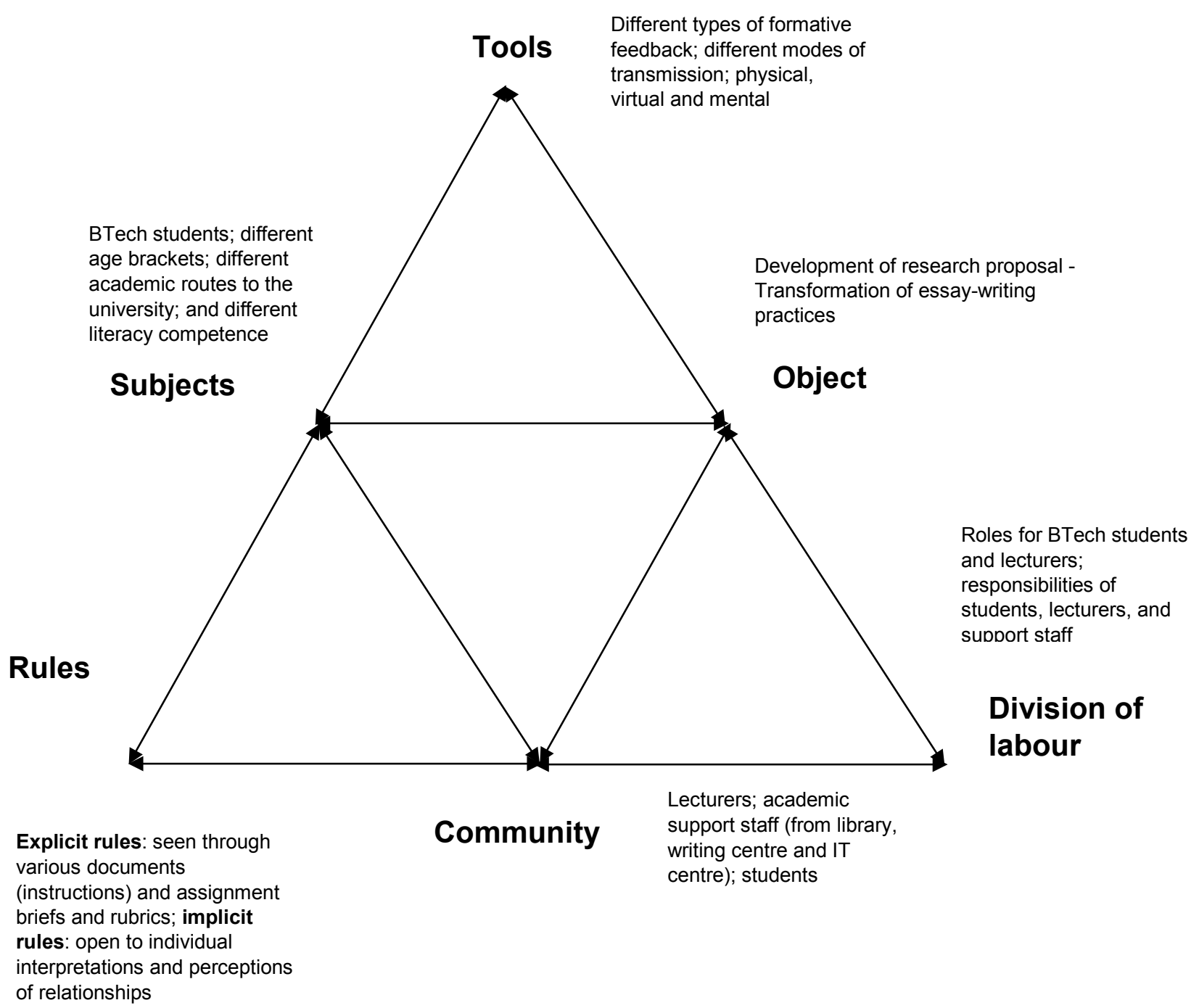

Figure 1: A formative feedback activity system (Adapted from Engeström 1987)

For Engeström (1999b), the subject in an activity system is an individual or group of people undertaking a particular activity. The subject is that person(s) who act on a tool in order to achieve the desired object. The assumed object of activity in this system is the BTech students' research proposal. As we would find later, this is only an assumed object and a source of tension in the writing activity. The 14 BTech students who participated in this study constitute the subject. Of interest is how culture and history influence the way they responded to formative feedback provided by their discipline-specific lecturers and the writing centre. Culture is used in this context to refer to the practices, values, dispositions (Archer 1995) that inform a way of doing and a way of being (Dall'Alba and Barnacle 2007) for dental technicians, irrespective of whether they are aware of it or not (Archer 1995). History refers to a genealogy of the discipline 
and how key moments in the past are influencing current practice (Engeström 2009). In order to understand this clearly, we need to profile the BTech Dental Technology student in the context of research writing as a social activity.

Dental Technology is a highly vocational discipline with a large portion of the curriculum focusing on laboratory work (Evans et al. 2010). In the South African context, this disciplinary culture does not favour postgraduate research because there are very little financial benefits that come with obtaining a Master's degree in the discipline as explained by Beryl below:

"It is not like we don't like research, Sir. You see, we need the BTech qualification because it qualifies us to be enrolled as dental technologist. With a National Diploma, you enrolled as a dental technician and you earn about R7000 less than a dental technologist. But with a BTech, you are a technologist. So, most of us will not come back for a master's degree because it has no significance in the laboratory. Whether you have a doctorate or masters, you are a technologist just like me with a BTech and we will earn the same because we do the same work" [Beryl, ${ }^{1}$ BTech Student].

Another student, Zizwe echoes Beryl's sentiments by asking the following questions:

"What are we going to do with all this research writing? I hear that they want us to come back for Masters studies. What are we going to do with a postgraduate qualification? Is there any lab in this country that specifically recruits dental technologists because they have a Master's degree? How many dental technologists in South Africa have Masters and $\mathrm{PhD}$ qualifications? Shouldn't we be spending more time learning more techniques and completing our practical?"

It is evident from the two responses above that these students have grown to see the BTech as the apex of their academic career in the discipline. Like many others whom they meet in the several dental laboratories, their target is to transition from being a dental technician to being a dental technologist. To fully understand the influence of culture in the students' perception about research writing, I follow up with one of the lecturers:

"It is true that the BTech qualification allows you to enroll as a dental technologist. That is what the South African Dental Council regulations stipulate. However, it is not exactly correct that there are no other benefits in pursuing postgraduate studies. With a master's or doctoral qualification, you can lecture in the university or supervise other postgraduate students and that would earn you some extra income. But the most important reason why we are really pushing the students to learn research writing is that it is an important step towards moving away from laboratory worker to becoming an innovator. We live in an age of rapid and massive technological innovations. It is important that our students master research writing so that they can participate actively in the global world of dental technological innovations. Unfortunately, these students do not see the bigger picture; they just want to go back to the laboratory and do what they love doing which is making stuff from the labs and earning a little bit more money as a technologist." [Mr Azaah, lecturer, Dental Theory]. 
From the excerpts above, it is evident that the dental technology student is conditioned by the culture, locally, in the dental technology discipline. The student, as a subject in a writing activity, faces the Research Methodology module within a certain psychological frame: that of economic and professional growth. They do not want to pursue postgraduate studies; and as such, their object within the writing activity is very different from the object of the writing activity as envisaged by the curriculum. This contradiction of subject-object relationship explains why the students are not motivated to learn research writing. They see research writing as an inconvenient obstacle on their path to enrolling as a dental technologist. Historically speaking, the lecturers and the students are not engaging in critical conversations about their encounters with research writing. Jolly and Boud (2013) and Boud and Molly (2013a) advise that in order to get students to act on feedback, the feedback process should allow for active participation through dialogue from the student to the lecturer. This dialogue can take the form of consultation and critical discussions between students and lecturers. In this way, the lecturer as the more knowledgeable other, should not only focus on the quality of the feedback that is written in response to the student's draft but should also find avenues to allow the student to respond to the learning task and feedback in a democratic and participatory manner. CHAT, therefore, allows us to see that there is mis-framing of the object in the writing activity system. For the student, the object of the writing activity is to pass Research Methodology which is a mandatory subject. For the lecturers, the object of the writing activity is to improve the students' knowledge of research methodology and competence of research writing. In the context of a vocational-intensive health science discipline such as dental technology where opinions about literacy practices often differs (Fraser and Killen 2005), it is important that lecturers demonstrate awareness of factors that will constrain students' ability to fully appreciate the object of a learning activity. Culturally speaking, research writing is not privileged in the dental laboratory, which is the BTech student's direct destination. This is prevalent in similar disciplines (such as medical laboratory technician) where a lot of work is done in the laboratory (Linder et al. 2014). This contradiction of the object in the writing activity is the source of the underlying tension between the lecturers and the students and prompted the invitation to the writing centre to mediate in the writing activity. Following from this realisation, it was possible to apply elements of dialogic feedback in supporting the students to complete the BTech research proposal.

\section{Tool: they choose the wrong spanner from the toolbox}

Developing from Vygotsky's concept of mediation in pedagogy, tool together with the subject 
and the object are the foundation of what Engeström later developed into an activity system in CHAT. Engeström's (1999b) notion of tools in an activity system encompasses the material, mental, and physical instruments used in an activity to transform the object. Dialogical formative feedback is examined in this study as the main mediating artifact used to transform BTech students' research-writing practices. Both the students and their lecturers agreed that formative feedback is the main tool in the writing activity as seen below:

"We received feedback from the lecturers and from you in the writing centre. However, it was very difficult to understand the tasks even when you guys wrote all the feedback. Remember that we started working on this research since March. As students, we had many group discussions but we didn't always make progress. It was only when the writing centre started these writing tutorial workshops that we began to understand clearly the different aspects of a research proposal. For me especially, I spent more than 3 months struggling to understand what a research objective is and what is a research question or the differences between research methodology and research methods. There were just too many terms that you have now explained step by step during these workshops that have helped me and most of us in this class to improve our research" [Vera, BTech Student].

The role of quality feedback as a tool was further highlighted by another student as follows:

"I think that when you asked us to do those short 5 minutes' presentations on specific aspects of our presentations, it helped us to see new things about our research. This is because, after each presentation, you spent time explaining where we were right and where we were wrong. Those sessions really helped us to re-write our research proposals in a more clear way." [Mark, BTech Student].

From the contributions of Vera and Mark, we notice that a two-way process of dialogue between the students and the lecturers is an effective way to solicit active student participation in the process of feedback generation and dissemination. Their narratives paint a picture of how the subject acts on the instrument to achieve the object. However, it is necessary to go back and examine how the tool was configured before we started the research writing tutorials. Similar to the subject-object interaction, it seems that there was a mis-framing of what the tool was before the tutorials commenced as testified by one of the lecturers:

"For me, the biggest contribution of the writing centre intervention is that it has revealed to us as lecturers the possibility to modify our pedagogic practice and rethink how we support the students. I never knew of dialogic feedback and the way you have organised the tutorials and involved us has been really enriching. I have been able to see clearly that before these tutorials, many of the students saw the research proposals as a means to pass the module." [Mr Brown, Research Methodology lecturer]. 
The last sentence from Mr Brown captures clearly the case of tool mis-framing in a writing activity. As supported by other students during the focus group discussions, the participants in the writing activity focused on the final grades of the module instead of the knowledge that the curriculum seeks to promote. Evidence was provided from the focus group discussions that this has been an on-going practice in the department, thus making it a cultural disposition. From a historical point of view, the students are not exposed to disciplinary experts who have pursued research beyond the BTech. At a surface level therefore, we notice this tension between subject, tools, and the community. There are, however, underlying factors contributing to these tensions. An understanding of history and culture from a CHAT perspective helps us to explain how and why these students have gradually developed apathy for research writing; and what needs to be done to change this. Once again, we find that through a diffractive reading of the dialogic feedback using CHAT, we are able to not only spot such mis-framing but to also demonstrate how more than one theory can be used in order to get a better insight to a problem. This kind of engagement makes a contribution to student learning, adds value to the notion of student success, and contributes positively to student well-being.

\section{Rules: Say what you mean and mean what you say}

An activity cannot take place in a void. More especially, writing is a social activity. The idea that writing is a social activity evokes variables such as a community involving people who perform different tasks and are guided by some rules. The base of Engeström's activity triangle speaks of rules, community, and division of labour. Rules in an activity system play the important role of defining how subjects should interact with the community when they make use of the tools (Winberg and Garraway 2016; Hardman 2005). Engeström (2009) indicates that rules can be explicit and implicit directives that control the way the subjects act or interact within the activity system. Engeström (1987) defines the community in an activity system as comprising different people or groups of people who operate within a specific setting and who share the same general object as distinct from other communities. The community in this study refers to students in other classes (peers), subject-specific lecturers, and learning support staff from the writing centre and library. This community is sometimes physical as in during writing workshops, and sometimes it is virtual as in during online collaboration facilitated through Google Docs. ${ }^{2}$ By division of labour, activity theorists refer to the roles and responsibilities which members who constitute the community share in order to reach the object jointly (Engeström 1999a). In this study, the subjects, as well as other members of the community, the lecturers, and the literacy support staff all had defined roles and responsibilities in contributing towards a better use of formative feedback during essay-writing practices. 
Discussions during the focus group interviews show several instances where rules that were thought to be explicit are instead implicit, and sometimes how this affected the way the students and lecturers interpreted their respective roles. Two such instances will be used to elucidate this. The first refers to the rules of submission of the research proposal:

\begin{abstract}
"We were given a brief in March indicating that we needed to submit the final proposal in October. It had all the specifications such as headings, formatting, word counts and all. In March, we thought we had sufficient time to write another essay like we have been writing all the other essay assignments. But we were so wrong. None of us in the class had understood anything about writing a research proposal. Nobody showed us an example of a research proposal. Most of the time, during Mr Brown's class, we focused on other stuff instead of the research methodology that he was teaching. If you didn't intervene from the writing centre, I'm not sure how we would have coped with this proposal." [Becks, BTech Student].
\end{abstract}

The process of engaging in a writing activity using dialogic feedback allows for a deeper appreciation of some of the taken-for-granted constraints that students face during research writing. As has already been explained, research writing is not foregrounded in dental technology practice in South Africa. Rather, the BTech students are mostly focused on perfecting their crafts as dental technologists and do not see the value of research writing. Furthermore, they have not had long exposure to and practice in research writing. Therefore, when an assignment brief for a research proposal is being submitted to the students, it should take into consideration their frame of reference and acknowledge the factors that will constrain the students' engagement with the writing task. This view was confirmed by Mr Brown when he remarked that:

"I think in future we should include these research writing tutorials very early in the year. We should include them in the timetable for the first semester, so that by the time we get to the second semester, the students would have covered a lot more than just focusing on their research proposal. We really want to build an environment where at least a few students can come back for a master's degree. We have had only 1 master's candidate in the last 4 years!" [Mr Brown, Research Methodology lecturer].

The above from Mr Brown demonstrates that he acknowledges that the students did not understand the rules of research proposal writing. While the lecturers thought that these rules were clear and explicit, the students had a completely different interpretation of them. This highlights the implicit-explicit disjuncture which has implications on how other members of the community interact with each other.

The second issue that poses the implicit-explicit conundrum refers to the rules of grammar in particular and writing style in general. Two students reported that they received feedback from their lecturer on an early draft of their research proposal in which the lecturer merely 
wrote:

"This is a serious research writing exercise, not a love letter. You must write in an academic style." [lecturer's feedback on student's draft proposal].

The students were justified to be confused. Without any formal lessons on language and style in research writing at BTech level, they did not know what their lecturer meant by inappropriate style. In this case, again, there is the assumption that the rules are explicit when they are not. Boud and Molloy (2013a) speak of formative feedback being provided in a caring manner. The notion of care in the provision of feedback during research writing is linked to trust (Carless 2013) and can be generated through active conversations between the students (who are the target of the feedback) and the lecturers (who are providing the feedback). In this way, the students begin to see these engagements not solely as summative assessments, but as developmental (Falchikov 2005), thus a contribution to their intellectual well-being. In a system whereby the lecturers have grown used to not having such critical conversations about writing, it becomes difficult for both parties to realise this disconnect. There is therefore a need to highlight the importance of good feedback practice as an intrinsic component of effective teaching in higher education (Vorster and Quinn 2015). Hassan (2011) cautions that not all lecturers are ready or trained to teach effectively. It is evident that "in the context of higher education, students and teachers are logically related to one another" with this relationship materialising either consistently or inconsistently (Vorster and Quinn 2017, 34). Through the use of dialogical feedback we are able to identify inconsistencies or contradictions; and also through the use of CHAT there is a clear explanation on how these tensions occur.

\section{IMPLICATIONS AND CONCLUSION}

This study explored the practice of formative feedback to a class of 14 dental technology students at a university of technology in South Africa. Based on a diffractive methodological approach, the article employed CHAT to examine how formative feedback during research writing is negotiated and appreciated between the students, the discipline-specific lecturers, and the writing centre, in the context of a vocational-intensive programme like dental technology. The article further examined the practice of formative feedback in the Dental Technology department through the dialogical approach to feedback proposed by Boud and Molloy (2013a, 2013b). The article thus documents how a diffractive reading of the practice of mediated feedback exchange in activity theory through a dialogical feedback approach brings to the fore important considerations on how we conceptualise and enact student learning support. Using 
experience and practice of academic writing support from the writing centre, the article demonstrates how two distinct set of ideas can interface and entangle to show a new appreciation of the value of formative feedback in academic literacy discourse.

Engeström's (1987) concept of an activity system employed as a basic unit of analysis read diffractively through Boud and Molloy's (2013a, 2013b) dialogical feedback challenges us to think carefully about the challenges that students face as they receive and act on feedback during a writing activity. Activity theory, just like a dialogical feedback approach, is based on a relational ontology framework which favours learning through mediation or "reflective activism" (Freire 1970, 60). By diffractively reading our thoughts and actions iteratively over time through the relational ontological frameworks of activity theory and dialogical feedback, this article proposes a breakaway from the formal, prosaic, linear, and bureaucratic approach of giving feedback to students' writing which often does not impact student learning. The way feedback is initiated, phrased and given (tools), the setting in which feedback interaction happens (community), the rules under which the student (subject) relates to the lecturers and other students (community), as well as the responsibilities that each have to adopt (division of labour), all contribute in how good formative feedback is mediated, transferred, and acted upon (Esambe et al. 2016). An activity system approach allows all concerned to take active roles in the process of negotiating feedback and acting on it. This results in feedback practice not being seen as a cruel and an unnecessary addition to lecturers' and students' workloads.

Dialogical feedback in a collaborative teaching and learning environment creates a space for rigorous engagements on not just students' writings as texts, but on the factors that enable or constrain their writings. This is especially important for teaching and learning in a health science context, where there is urgent need to transform pedagogical practices (The Lancet Commissions 2010). In the case of the interventions presented in this article, we see an increasing and a more nuanced appreciation of formative feedback by all the stakeholders. This converts the place of formative feedback in the learning community from just a tool to justify a particular mark to a powerful cultural tool as explained below:

"There is not a clear moment when an artefact transforms into a cultural tool, but a cultural tool is an artefact that has gained value within participants' activities rather than as a temporary tool for engaging in an immediate activity." (Yamagata-Lynch 2010, 17).

A conscious and active engagement between lecturers (who are in the centre of the teaching and learning project, and thus in a position of power) and students (who are in the fringes of the academic community in terms of not being in control of what is being taught and how this teaching occurs) can be achieved through critical conversations. Critical conversations about 
taken for granted ways of doing and being in the discipline, proposed through the notion of dialogic formative feedback, is transformative and an empowering approach to teaching research writing. Honesty is an important element in the process of negotiating good formative feedback (Carless, 2013; Lillis 2011). However, honesty cannot be guaranteed merely because you have a classroom with students and lecturers. Elements of the dialogical approach allow the lecturers and students to pose questions and provide responses that engender learning in a collective and collaborative way. Such proactive collaborative practices (Nicol 2013) provide further learning outcomes for the students beyond the university. It presents to the students, unique opportunities in which to model workplace and professional interactions in the spirit of collaboration.

\section{LIMITATION}

This article explored a small group of students' engagements and reactions to formative feedback practice in a vocational-intensive programme. Set in the Department of Dental Sciences at a health faculty, the research sample is 14 students and 2 lecturers. While this sample size is relevant and supports the generation of qualitative data, the findings from this research cannot be generalised. A more extensive research covering other departments and other universities, as well as using both quantitative and qualitative data will give a broader view of the state of formative feedback practices in vocational-intensive programmes in the South African higher education landscape. Furthermore, while CHAT and dialogical formative feedback were useful analytical lenses to probe how support is provided to students learning research writing in difficult settings, these theories do not allow us to probe the depth of learning taking place. Further studies could employ a knowledge-based theory such as Legitimation Code Theory to explore the depth of learning taking place during such tutorials.

\section{DISCLOSURE STATEMENT}

This article is a product of the Cape Peninsula University of Technology (CPUT's) Research and Innovation Fund for Teaching and Learning (RIFTAL) funded investigation on the role of the institutional Writing Centre in supporting student learning in different contexts. Sincere acknowledgement is extended to the Professional Education Research Institute (PERI) and Professor Chris Winberg for organising a Research Writing Retreat to Montfleur (Stellenbosch) where this article was drafted.

\section{NOTES}

1. Participants have been given pseudonyms to maintain their anonymity. 
2. Google Docs is a free-to-access online application which serves as a host for different kinds of documents. These documents can be shared amongst users and editing can take place in realtime.

\section{REFERENCES}

Archer, M. S. 1995. Realist social theory: The morphogenetic approach. Cambridge: Cambridge University Press.

Barad, K. 2007. Meeting the universe halfway: Quantum Physics and the entanglement of matter and meaning. Durham, NC: Duke University Press.

Boud, D. and E. Molloy. 2013a. What is the problem with feedback? In Feedback in higher and professional education: Understanding it and doing it well, ed. D. Boud and E. Molloy, 1-10. London: Routledge.

Boud, D. and E. Molloy. 2013b. Rethinking models of feedback for learning: The challenge of design. Assessment \& Evaluation in Higher Education 38(6): 698-712.

Bozalek, V., V. Mitchell, A. Dison and M. Alperstein. 2016. A diffractive reading dialogical feedback through the political ethics of care. Teaching in Higher Education DOI: 10.1080/13562517.2016.1183612.

Carless, D. 2013. Trust and its role in facilitating dialogic feedback. In Feedback in higher and professional education: Understanding it and doing it well, ed. D. Boud and E. Molloy, 90-10. London: Routledge.

CHE see Council on Higher Education.

Council on Higher Education. 2009. Postgraduate studies in South Africa: A statistical profile. Higher Education Monitor 7. http://www.che.ac.za/sites/default/files/publications/CHE_Monitor ProjectV7.pdf (Accessed 13 May 2017).

Christensen, G. J. 2009. Improving dentist-technician interaction and communication. The Journal of the American Dental Association 140: 475-478.

Clarence, S. 2017. A relational approach to building knowledge through academic writing: Facilitating and reflecting on peer writing tutorials. In Writing centre in higher education: Working in and across the disciplines, ed. S. Clarence and L. Dison, 49-68. Stellenbosch: SUN Press.

Clarence, S. and S. McKenna. 2017. Developing academic literacies through understanding the nature of disciplinary knowledge. London Review of Education 15(1): 38-48.

Dall'Alba, G. and R. Barnacle. 2007. An ontological turn for higher education. Studies in Higher Education 32(6): 679-691.

Dolphijn, R. and I. Van Der Tuin. 2012. New materialism: Interviews and Cartographies. Ann Arbor, MI: University of Michigan Library.

Engeström, Y. 2009. The future of activity theory: A rough draft. In Learning and expanding with activity theory, ed. A. Sannino et al., 303-328. Cambridge: Cambridge University Press.

Engeström, Y. 1999a. Activity theory and individual and social transformation. In Perspectives on activity theory, ed. Y. Engeström et al., 19-38. Cambridge: Cambridge University Press.

Engeström, Y. 1999b. Innovative learning in work teams: Analysing cycles of knowledge creation in practice. In Perspectives on activity theory, ed. Y. Engeström et al., 377-404. Cambridge: Cambridge University Press.

Engeström, Y. 1987. Learning by expanding: An activity-theoretical approach to developmental research. Helsinki: Orienta-Konsultit.

English, F. 2015. Genre as a pedagogical resource at university. In Working with academic literacies: Case studies towards transformative practices, ed. T. Lillis et al., 245-255. Colorado: WAC Clearing House/ Parlour Press.

Esambe, E., C. Mosito and S. Pather. 2016. First-year students' essay writing practices: Formative 
feedback and interim literacies. Reading \& Writing 7(1). DOI: https://doi.org/10.4102/rw.v7i1.87

Evans, J., A. Henderson and N. Johnson. 2010. The future of education and training in dental technology: Designing a dental curriculum that facilitates teamwork across oral health professionals. British Dental Journal 208(5): 227-230.

Falchikov, N. 2005. Improving assessment through student involvement: Practical solutions for aiding learning in higher and further education. New York: Routledge.

Fraser, W. and R. Killen. 2005. The perceptions of students and lecturers of some factors influencing academic performance at two South African universities. Perspectives in Education 23(1): 25-40.

Freire, P. 1970. Pedagogy of the oppressed. New York: Continuum.

Gándara, P., R. Rumberger, J. Maxwell-Jolly and R. Callahan. 2003. English learners in California schools: Unequal resources, unequal outcomes. Education Policy Analysis Archives, 11(36). http://epaa.asu.edu/epaa/v11n36/ (Accessed 26 May 2018).

Gardner, S. K. 2009. Student and faculty attributions of attrition in high and low-completing doctoral programmes in the United States. Higher Education 58(1): 97-112.

Gee, J. P. 2008. Social linguistics and literacies: Ideology in discourses. London: Routledge.

Hardman, J. 2005. Activity theory as a framework for understanding teachers' perceptions of computer usage at a primary school level in South Africa. South African Journal of Education 25(4): 258 265.

Hardman, J. and A. Amory. 2015. Introduction to cultural-historical activity theory and tool mediation. In Activity theory, authentic learning and emerging technologies: Towards a transformative higher education pedagogy, ed. V. Bozalek et al., 9-21. New York: Routledge.

Hassan, S. 2011. The needs and perceptions of academics regarding their professional development in an era of educational transformation. South African Journal of Higher Education 25(3): 476-490.

Herman, C. 2011. Obstacles to success - doctoral student attrition in South Africa. Perspectives in Education: The Changing face of Doctoral Education in South Africa (Special Issue) 3: 40-52.

Hultman, K. and H. Lenz Taguchi. 2010. Challenging anthropocentric analysis of visual data: A relational materialist methodological approach to educational research. International Journal of Qualitative Studies in Education 23: 525-542.

Jacobs, C. 2013. Academic literacies and the question of knowledge. Journal for Language Teaching 47(2): 127-140.

Jolly, B. and D. Boud. 2013. Written feedback: What it is good for and how can we do it well. In: Feedback in higher and professional education: Understanding it and doing it well, ed. D. Boud and E. Molloy, 104-124. London: Routledge.

Koen, C. 2007. Postraduate student retention and success: A South African case study. Cape Town: HSRC Press.

Lea, M. 2016. Academic literacies: Looking back in order to look forward. CriSTaL: Critical Studies in Teaching and Learning, 4(2): 88-101. DOI: http://10.14426/cristal.v4i2.91.

Lillis, T. and M. Scott. 2007. Defining academic literacies research: Issues of epistemology, ideology and strategy. Journal of Applied Linguistics 4(1): 5-32.

Lillis, T. 2011. Legitimizing dialogue as textual and ideological goal in academic writing for assessment and publication. Arts and Humanities in Higher Education 10(4): 401-432.

Linder, A., J. Airey, N. Mayaba and P. Webb. 2014. Fostering disciplinary literacy? South African Physics lecturers' educational responses to their students' lack of representational competence. African Journal of Research in Mathematics Science and Technology Education 18(3): 242-252.

Maclure, M. (2013). Researching without representation? Language and materiality in post-qualitative methodology. International Journal of Qualitative Studies in Education 26(6): 658-667.

Motshoane, P. and S. McKenna. 2014. More than agency: The multiple mechanisms affecting postgraduate education. In Pushing boundaries in postgraduate supervision, ed. E. Bitzer, R. 
Albertyn, L. Frick, B. Grant and F. Kelly, 199-214. Stellenbosch: SUN Media.

Nicol, D. 2013. Resituating feedback from the reactive to the proactive. In Feedback in higher and professional education: Understanding it and doing it well, ed. D. Boud and E. Molloy, 34-49. London: Routledge.

North, S. M. 1984. The idea of a writing centre. College English 46(5): 433-446.

Prinsloo, P. 2016. A socio-critical model for understanding and predicting postgraduate student success. In Postgraduate supervision: Future foci for the knowledge society, ed. M. Fourie-Malherbe et al., 85-98. Stellenbosch: SUN Press.

Robinson, H. M. 2009. Writing centre philosophy and the end of basic writing: Motivation at the site of remediation and discovery. Journal of Basic Writing 28(2): 70-92.

Rowe, M., V. Bozalek and J. Frantz. 2013. Using Google Drive to facilitate a blended approach to authentic learning. British Journal of Educational Technology 44(4): 594-606.

SADTC see South African Dental Technicians Council.

South African Dental Technicians Council. 2017. Scope of profession. https://www.sadtc.org.za/theprofession/scope-of-profession.html (Accessed 20 June 2017).

The Lancet Commissions. 2010. Health professionals for a new century: Transforming education to strengthen health systems in an interdependent world. The Lancet 376(9756): 1923-1958. DOI: https://doi.org/10.1016/S0140-6736(10)61854-5.

Thompson, I. 2009. Scaffolding in the writing centre: A microanalysis of an experienced tutor's verbal and nonverbal strategies. Written Communication 26(4): 417-446.

Tinto, V. 2014. Tinto's South Africa lectures. Journal of Student Affairs in Africa 2(2): 5-28. DOI: 10.14426/jsaa.v2i2.66.

Vorster, J. and L. Quinn. 2015. Towards shaping the field: Theorising the knowledge in a formal course for academic developers. Higher Education Research and Development 53(5): 1031-1044.

Vorster, J. and L. Quinn. 2017. The "decolonial turn": What does it mean for academic staff development? Education as Change 21(1): 31-49. DOI: http://dx.doi.org/10.17159/19479417/2017/853.

Winberg, C. and J. Garraway. 2016. "It takes a villlage": Attaining teaching excellence in a challenging context. South African Journal of Higher Education 30(6): 161-175.

Yamagata-Lynch, L. C. 2010. Activity systems analysis methods: Understanding complex learning environments. New York: Springer. 